\title{
Design of Dual Mode RFID Antenna for Inventory Management and IV Fluid Level Warning System
}

\author{
Ssu-Han Ting, ${ }^{1}$ Chih-Kuang Wu, ${ }^{2}$ and Ching-Hsing Luo ${ }^{1,3}$ \\ ${ }^{1}$ Department of Electrical Engineering, National Cheng Kung University, Tainan 701, Taiwan \\ ${ }^{2}$ Department of Electrical Engineering, Southern Taiwan University of Science and Technology, Tainan 710, Taiwan \\ ${ }^{3}$ School of Data and Computer Science, Sun Yat-sen University, Guangzhou, Guangdong 510006, China \\ Correspondence should be addressed to Ching-Hsing Luo; robin@ee.ncku.edu.tw
}

Received 26 July 2016; Revised 8 December 2016; Accepted 28 December 2016; Published 12 April 2017

Academic Editor: Luciano Tarricone

Copyright (C) 2017 Ssu-Han Ting et al. This is an open access article distributed under the Creative Commons Attribution License, which permits unrestricted use, distribution, and reproduction in any medium, provided the original work is properly cited.

Radio frequency identification (RFID) readers are powered RF devices that communicate with an RFID tag to read necessary information. Using this capability, a dual use system for short distance inventory management and moderate distance automatic warning system for low intravenous (IV) fluid levels is designed. The RFID is affixed on the IV drip bag; the fluid in bag affects the antenna transmission distance by fluid dielectric conditions. This allows for two different operational modes (moderate and short distance). For pharmaceutical management, a handheld RFID reader can be used for short distance application. Another stationary RFID system can serve as a warning system for long distance application such as hospital care.

\section{Introduction}

Given the current shortage of medical and nursing staff, in the future, the development of information technology will inevitably affect the healthcare system and its practices. Healthcare practices must adapt to the challenges of expenses versus assets for elderly people [1]. Use of information technology in different operations can improve patient's safety and nursing efficiency and therefore decrease healthcare expenses [2]. In order to reduce the surgery and drugrelated error, some management system has been proposed, in which radio frequency identification (RFID) was used to enhance the identification healthcare, tracking of critical surgery procedures, and control or safety of medications and medical materials [3-5]. The drug name of the intravenous (IV) fluid is usually checked manually by a nurse during application, though not always without error. When the fluid inside the drip bag is nearly empty, the situation is usually detected from periodic visual inspection by a nurse or by the patient alerting the nurse desk by call button. This procedure results in frequent interruption of nurse tasks and increases personnel cost. Therefore, inventory management and warning systems can be practically applied for assisting nurses. Recently, this type of detection warning system has been explored in many relevant studies [5-9]. In these studies, the monitoring of fluid level (or volume) is performed through several methods, including optical systems, ultrasonic or capacitive sensors, and microwave sensing. In particular, time domain microwave reflectometry (TDR) has proven to be a powerful and effective method for quantitative characterization of several fluids. However, this commonly involves insertion of a specific sensing probe to monitor the dielectric characteristics of the fluid. The drawback of this method is cost from equipment and/or additional manual procedures.

Since its invention after World War II, RFID (Radio Frequency Identification) [10] has been applied in diverse areas for private, scientific, and industrial purposes. RFID tags allow objects to be identified wirelessly. These tags are classified into two types, namely, active or passive depending on whether they are internally or externally powered. In this design, ultra high frequency (UHF) passive tags are applied for this system (UHF and microwave bands). That is, the antenna does not perform well near highly electromagnetic lossy objects. When a tag is attached on or near these kinds of materials, for example, bottles containing fluid or metals, 


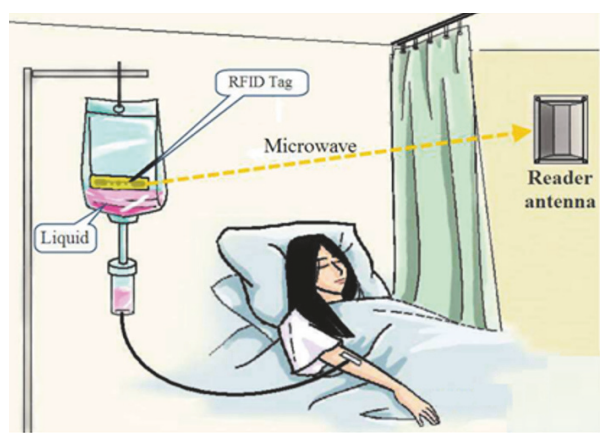

(a)

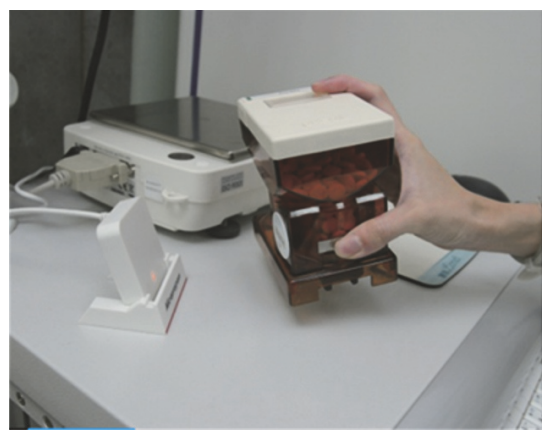

(b)

FIGURE 1: RFID warning and pharmaceutical management system. (a) Using at long distance for warning system. (b) Using at short distance for pharmaceutical management system.

it will be not able to echo the RF signal from the RFID reader. In this work, a warning and medication management system for intravenous drip monitoring is conceived. Information Technology (IT) and RFID become quite useful technologies for the enhancement of healthcare and patient management [11]. There is, however, a shortage of studies on the impact of RFID technology on patient management-related processes. This study intends to fill this knowledge gap in literature by unveiling the potential of RFID enabled intelligent patient management. Twelve patient management-related processes are identified, followed by the assessment of the impact of RFID on the said processes by a panel of experts using a three-round Delphi study. The study identifies the top five processes that may benefit from RFID technology as follows: (1) accurate patient identification for medication safety; (2) patient identification to avoid wrong drug dosage; (3) accurate patient identification; (4) infant identification in hospitals to avoid mismatching; and (5) tracking of drug supplies and procedures performed on each patient. Furthermore, the evaluation of standard deviation variation shows a high convergence of consensus among the members of the panel with regard to nine of the twelve processes. Finally, the paper discusses future research directions. Figure 1 shows the proposed idea of an RFID tag on the intravenous drip bag. Specifically, the tag is affixed to the lowest position of the plastic or rubber IV bag full of injection fluid. In this work, the injection fluid itself is used to change the antenna resonance mode for two different applications. When the bag is full, the antenna resonant mode is almost $400 \mathrm{MHz}$ with the harmonic at about $915 \mathrm{MHz}$, so $915 \mathrm{MHz}$ is chosen for this RFID system. Although the injection fluid is a lossy object and reduces the distance of RF signal from the RFID reader, it still can be used for inventory management at short distances. When the IV bag is in use, this moderate distance RFID system will give warning when low IV fluid conditions allows the first resonant mode to drift to $915 \mathrm{MHz}$.

The procedure of designing a RFID tag by considering the material parameters of the bag of intravenous trip is described in the following text. In this work, the tag prototype is designed based on the concept of complex conjugated match between the chip and the associated antenna and is fabricated on a PCB. Such a design offers a low-cost solution for mass deployment for a hospital medication management system. Furthermore, these tags are recyclable and environmentally friendly.

\section{Antenna Design}

2.1. Antenna Simulation Environment. Using dipole type to design the tag antenna had been proposed by lots of researches $[12,13]$. IV drips are common in hospitals, and the most commonly used are dextrose and saline. Using an IV may take several hours. When the IV is finished, prompt removal needle prevents issues such as blood reflux. Therefore, the nurse must vigilantly monitor the situation. In this paper, a RFID inventory management and warning system based on dual mode tag antenna is presented. The features in this design use the dielectric constant of the injection fluid to change the antenna resonance mode. Before antenna design, the dielectric constant of the target fluids is measured. Figure 2 presents the test environment for dielectric measurement of the fluids (dextrose and saline (dextrose is $5 \%$ in normal saline and normal saline is $0.9 \% \mathrm{w} / \mathrm{v})$ ) on an Agilent $85070 \mathrm{E}$ dielectric probe kit and an $8753 \mathrm{E}$ network analyzer. Figure 3 shows the comparison results of permittivity and conductivity versus frequency between dextrose and saline. The measurement results are very similar, so this antenna can be used for both fluids.

2.2. Antenna Geometry. For this system, characteristics are modeled by an Ansoft simulation software high frequency structure simulator $\left(\mathrm{HFSS}^{\mathrm{TM}}\right.$ ). Figure 4 shows the designed antenna top view geometry and structure, and all parameters are shown below. The size of the tag is $6 \times 120 \times 0.8 \mathrm{~mm}^{3}$. Figures 5(a) and 5(b) show, respectively, the antenna crosssectional and top view while affixed to the IV bag. The first layer is $0.8 \mathrm{~mm}$ thick glass-reinforced epoxy laminate FR-4. The second layer is the PVC IV bag having $2 \mathrm{~mm}$ thickness. Third layer is injection fluid (dextrose or sodium) whose thickness is $40 \mathrm{~mm}$. Due to the antenna being used in a complex environment, all materials are modeled in the simulation for more reliable results [14]. 


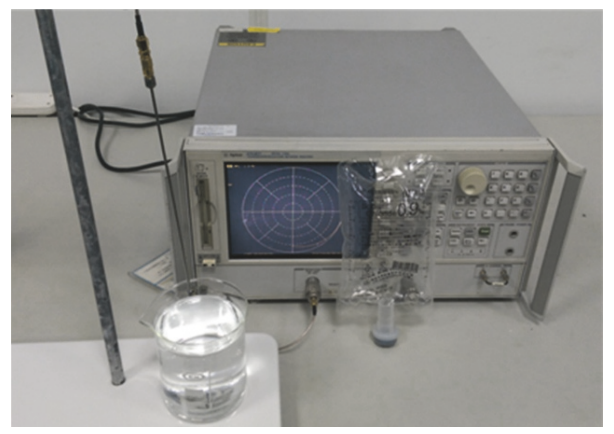

FIGURE 2: IV fluid permittivity and conductivity measurement environment.
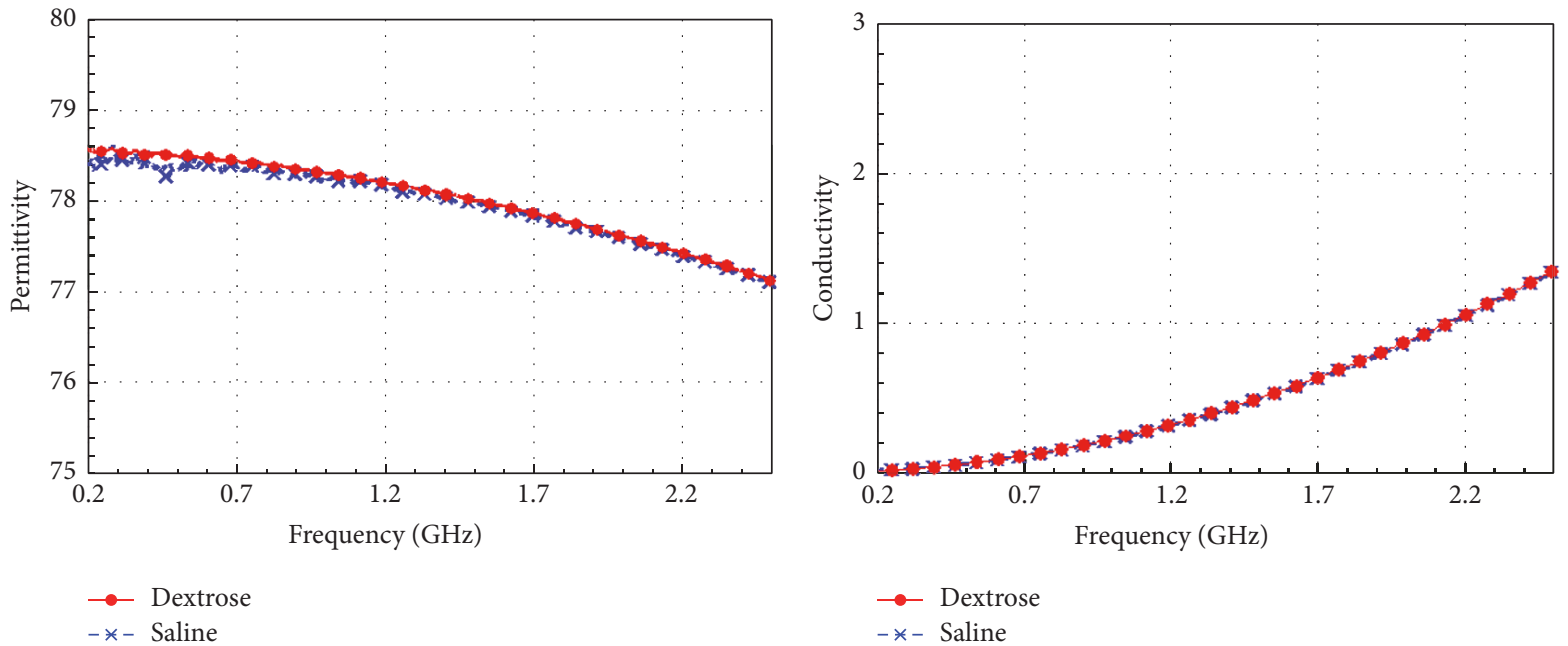

FIGURE 3: Injection fluid measured permittivity and conductivity.

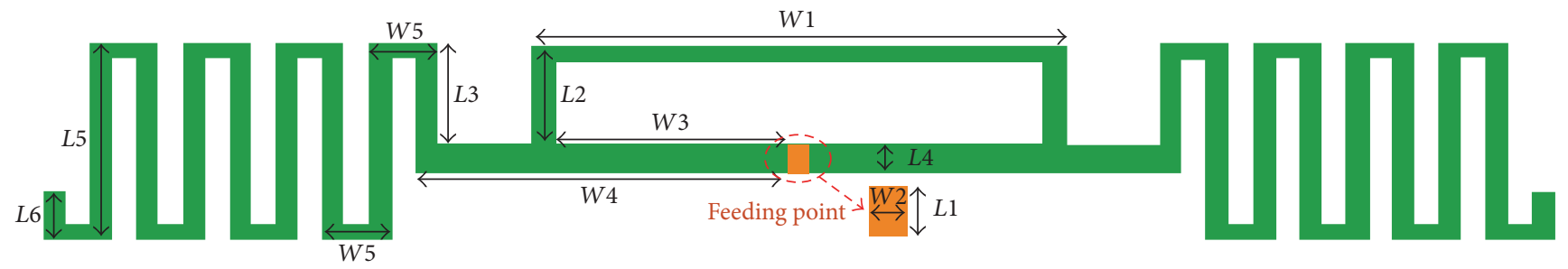

Figure 4: Antenna top view geometry: $L 1=5.8 \mathrm{~mm}, L 2=6 \mathrm{~mm}, L 3=6.2 \mathrm{~mm}, L 4=1.8 \mathrm{~mm}, L 5=12 \mathrm{~mm}, L 6=3 \mathrm{~mm}, W 1=23 \mathrm{~mm}$, $W 2=1 \mathrm{~mm}, W 3=7 \mathrm{~mm}, W 4=13 \mathrm{~mm}$, and $W 5=3 \mathrm{~mm}$.

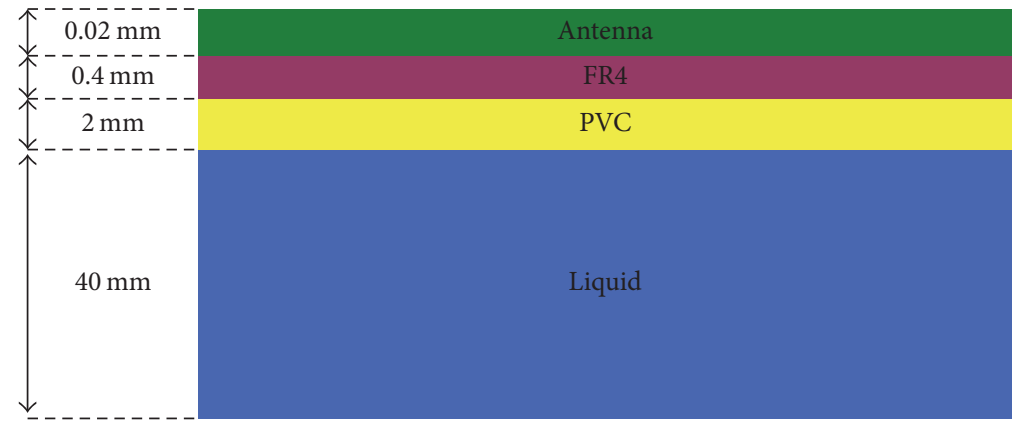

(a)

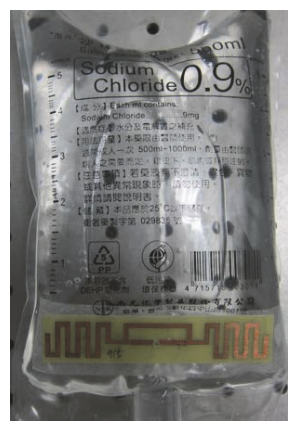

(b)

FIgURE 5: (a) Cross-sectional view of tag affixed to IV bag. (b) Top view of tag affixed to IV bag. 

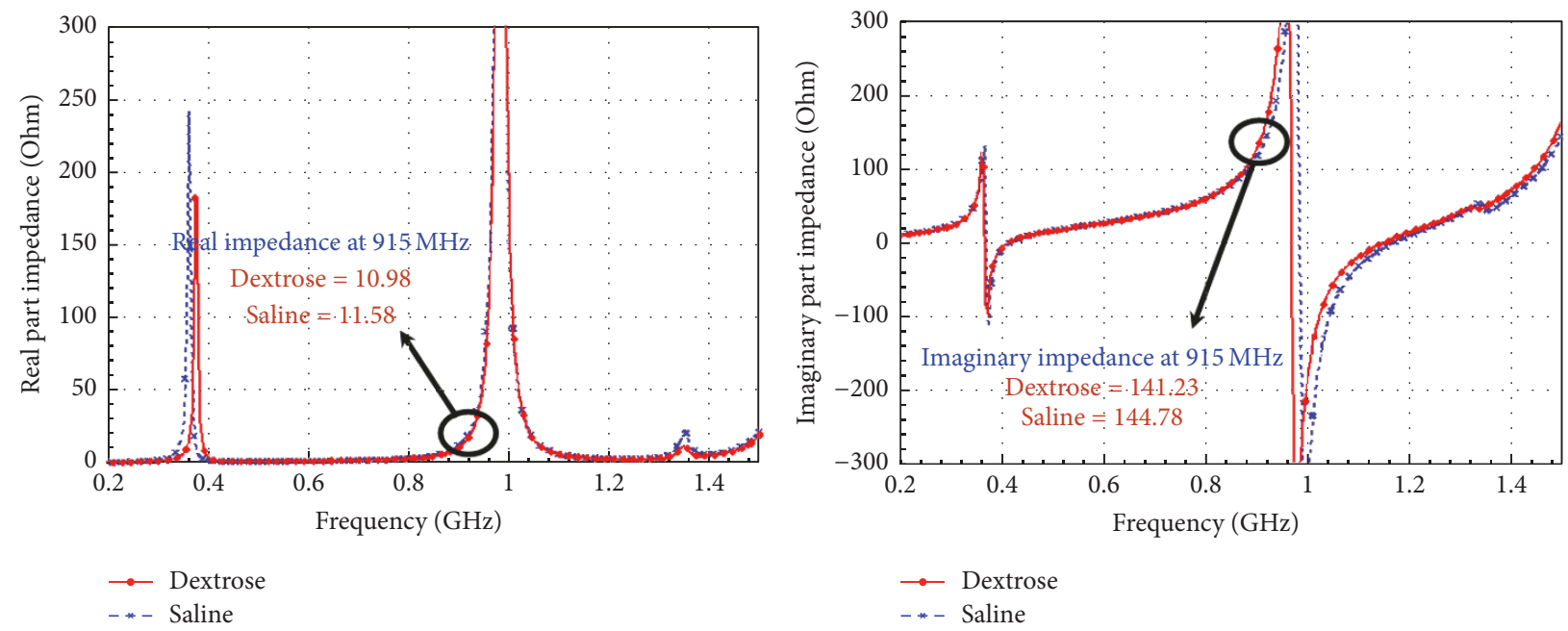

FIGURE 6: Simulated antenna impedance for tag on injection fluid.

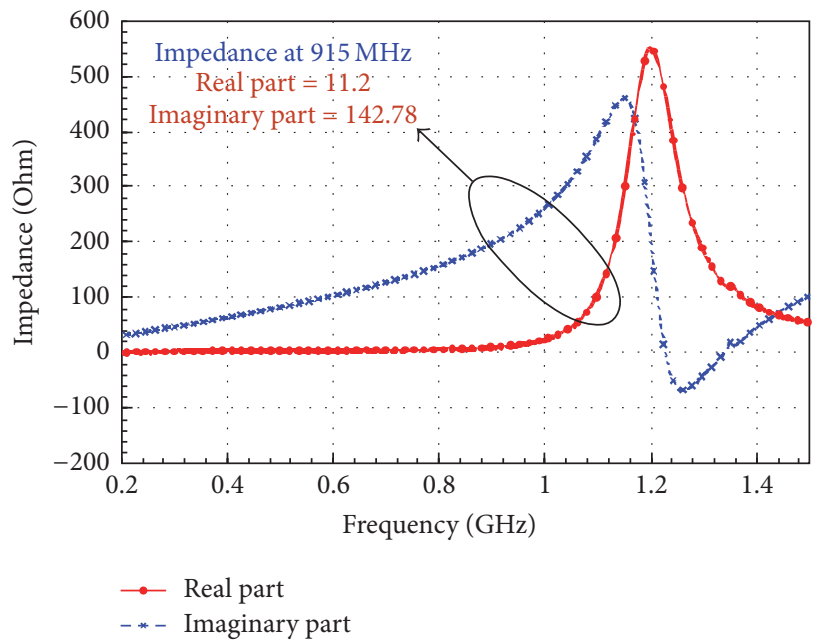

FIGURE 7: Simulated antenna impedance in air.

\section{Results and Discussion}

In the design phase, the input impedance of the chip and antenna follows the concept of complex conjugated matching for optimal transfer efficiency [15]. The Impinj M4 [16] IC was chosen for the tag. It has output impedance of $11-j 143 \Omega$. So for good transfer efficiency, the antenna impedance must be close to $11+j 143 \Omega$. Currently, most tags used in the industry have a planar dipole design and are manufactured by PCB technology. However, with recent printing technology advancements [17], tag production has seen lowered costs. For this design, the tag antenna must be able to satisfy the two modes of short distance inventory management and moderate distance IV level warning system. Figure 6 shows the antenna simulation impedance results. The first resonance mode is about $400 \mathrm{MHz}$ and its harmonic is about $915 \mathrm{MHz}$. The antenna impedance is $10.98+j 141.23 \Omega$ and $11.58+$ $j 144.78 \Omega$ for dextrose and saline, respectively. Figure 7 is the simulated antenna impedance of low IV fluid conditions. In these simulated results, the first resonance mode shifts to higher frequency $(915 \mathrm{MHz})$ with antenna impedance of $11.22+j 142.78 \Omega$.

Figure 8 shows the antenna current distribution in fluid (dextrose and saline) and air. In this figure, when the antenna is affixed on the full IV bag, the current distribution is very similar for both fluids and the resonance mode is almost one wavelength at $915 \mathrm{MHz}$. Current distribution on air is shown in Figure 8(c), and the resonance mode is almost half wavelength at $915 \mathrm{MHz}$. From Figures 6, 7, and 8, the antenna has different resonance modes with and without fluid, which allows this design to detect fluid levels.

The test environment is clearly demonstrated with the position of tag antenna and reader systems shown in Figure 9. The criterion of the warning system is determined by the signal intensity at reader; the results are shown in Figure 10. Once the warning level is reached, the system confirms the 


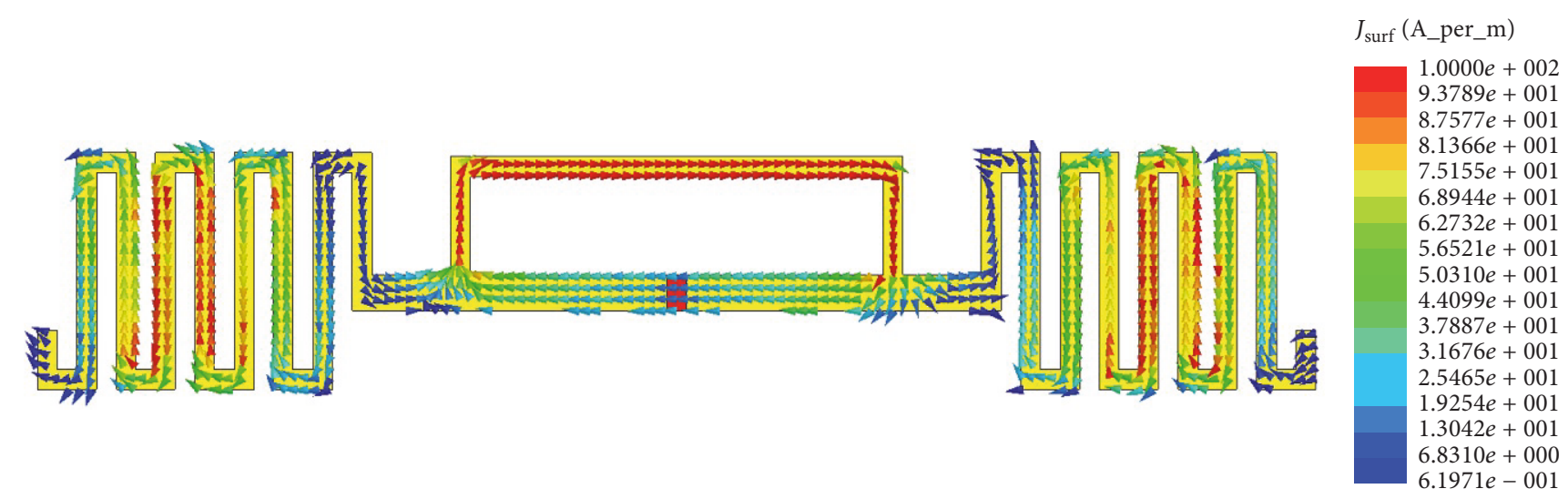

(a)

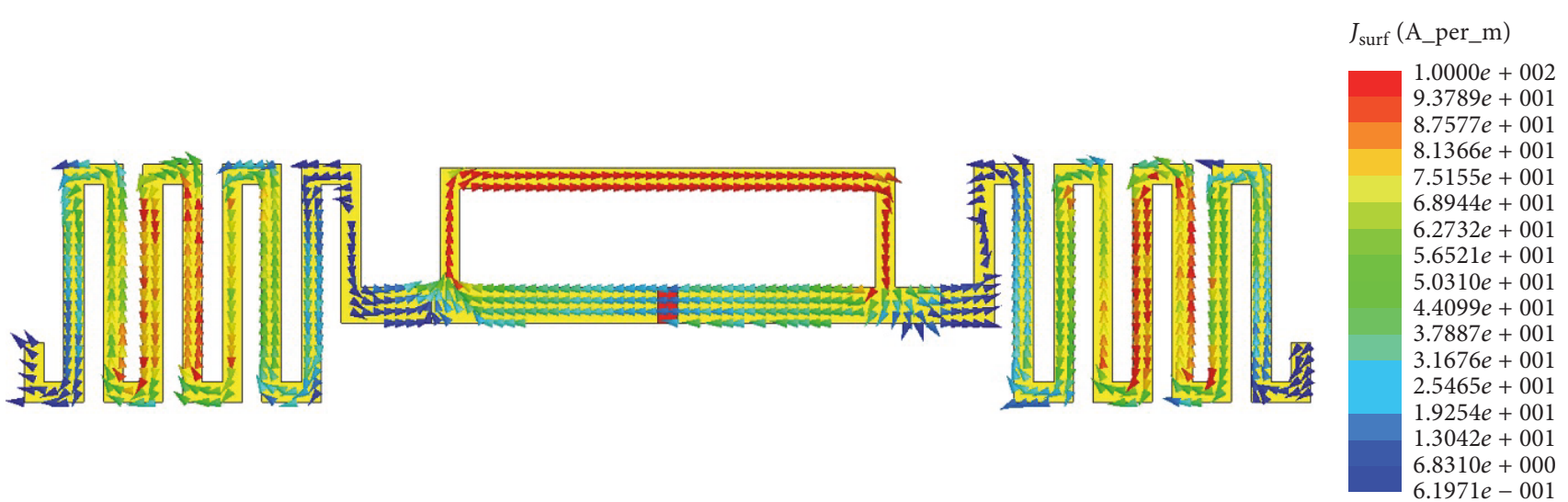

(b)

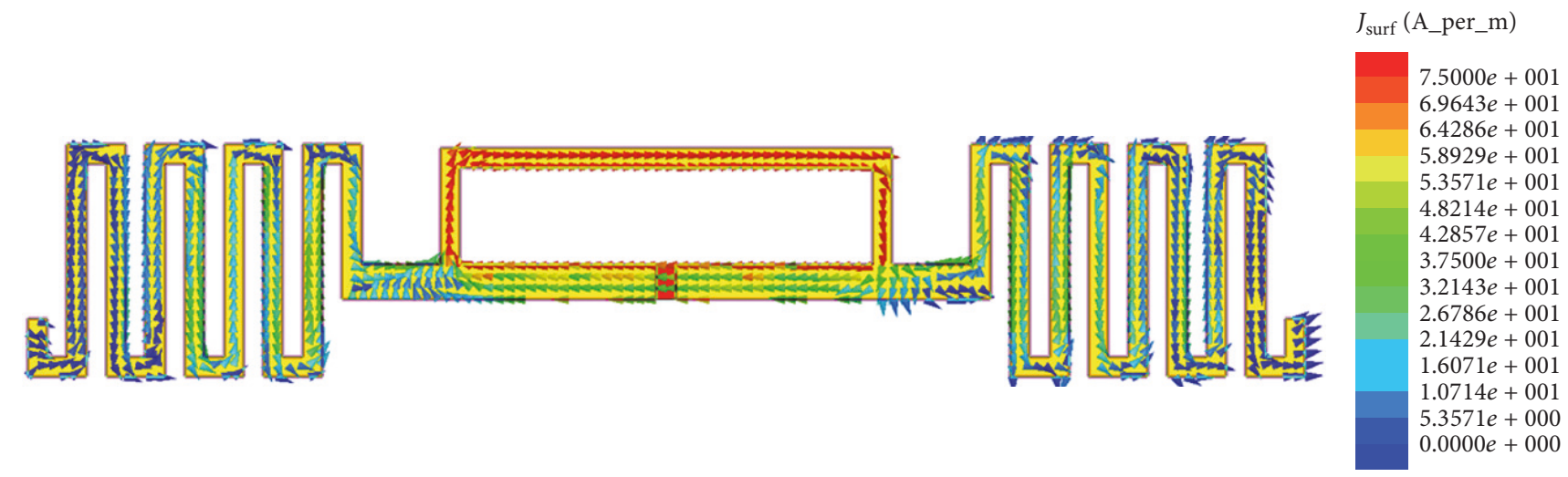

(c)

Figure 8: Antenna current distribution at $915 \mathrm{MHz}$ : (a) antenna on dextrose, (b) antenna on saline, and (c) antenna in air.

tag ID to send out warning message. The physical system test environment uses the AS3992 reader module (USB linked long range UHF Gen 2 single chip reader) and controlling PC. This system has a $3 \mathrm{dBi}$ circular polarization antenna to receive and transmit signals. System test results are shown in Figure 11. The first transmission distance is short $(30 \mathrm{~cm})$ and is suitable for hospital inventory management. The system warns when the IV fluid level is lower than $20 \mathrm{ml}$. For this second situation, the transmission distance is longer $(340 \mathrm{~cm})$ and covers the length of a single bed. System testing demonstrates that the dual mode RFID tag antenna is suitable for both IV fluid level warnings and hospital inventory.

The RFID tag antenna is attached to the bag $(500 \mathrm{ml})$ bottom in the following figure (about $20 \mathrm{ml}$ level). Figure 12 shows the antenna location. When liquid is more than $20 \mathrm{ml}$ (antenna is covered with liquid) it absorbs most of the radiation, so the tag cannot have long distance transmission. While liquid is equal to or less than $20 \mathrm{ml}$ for the antenna radiation arm partially exposed to air, in this moment both the dielectric constant and transmission distance start to 


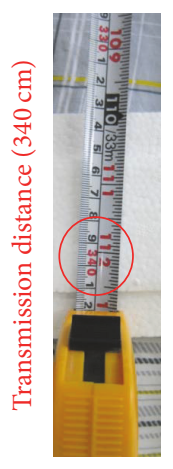

(a)

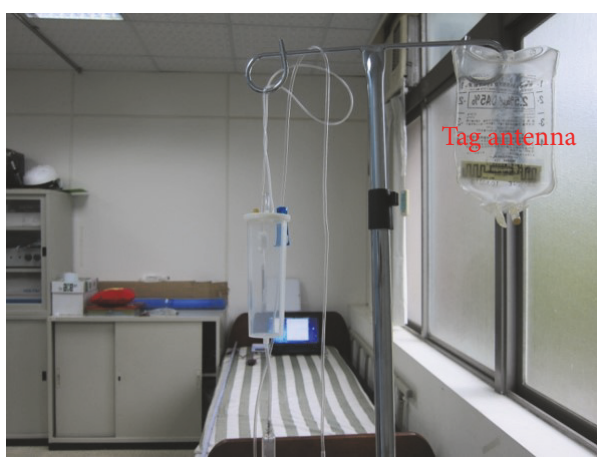

(b)

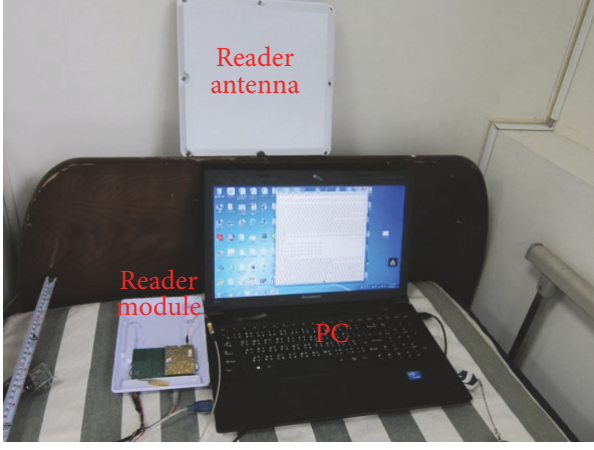

(c)

Figure 9: Test environment: (a) transmission distance, (b) the position where the tag antenna is located, and (c) reader antenna, reader module, and PC.

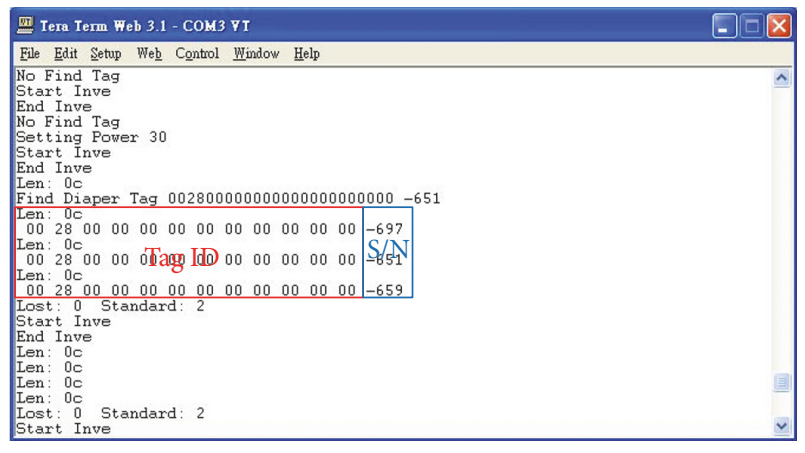

FIGURE 10: Software information to show tag ID and S/N.

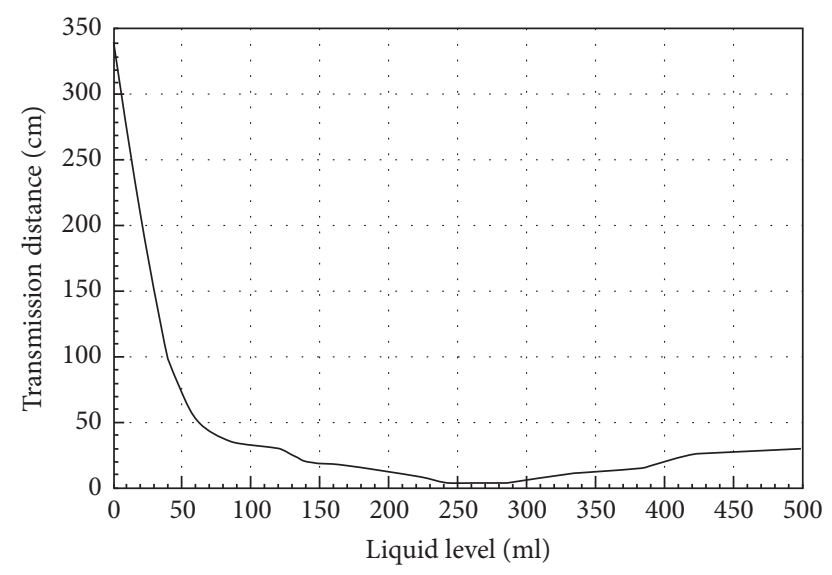

FIGURE 11: Overall system test results.

change. The feature in this manuscript is using the liquid to switch transmission distance for different operation. We also used this system to do repetitive verification. Some reliability tests are shown in Table 1. Transmission distance is defined as a sickbed length of about $230 \mathrm{~cm}$. Using these measured results we can get the mean $(\mu)$ and standard deviation $(\sigma)$.

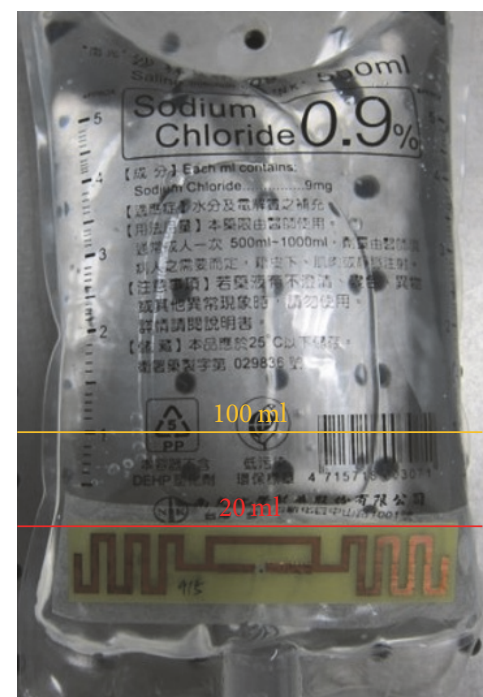

FIgURE 12: Antenna location.

By normal probability distribution calculation we can get the warning interval. The warning internal is 12.6 to $7.3 \mathrm{ml}$, and in this internal the accuracy reported is up to $96 \%$.

\section{Conclusion}

This paper presented a dual mode RFID tag antenna which effectively changes antenna mode according to IV bag fluid levels. These two different use modes allow for application in inventory management and low fluid warning. In a hospital setting, this system provides a method for managing IV use and inventory to reduce nurse workloads.

\section{Conflicts of Interest}

The authors declare that they have no conflicts of interest. 
TABLE 1: Link to system test results.

\begin{tabular}{lc}
\hline \multicolumn{3}{c}{ Transmission distance $230 \mathrm{~cm}$} \\
Liquid $(\mathrm{ml})$ & Link to reader system \\
\hline 20 & Yes \\
19 & Yes \\
18 & Yes \\
17 & Yes \\
16 & Yes \\
15 & Yes \\
14 & Yes \\
13 & Yes \\
12 & Yes \\
11 & Yes \\
10 & Yes \\
9 & Yes \\
8 & Yes \\
7 & Yes \\
6 & Yes \\
5 & Yes \\
4 & Yes \\
3 & Yes \\
2 & Yes \\
1 & Yes \\
0 & Yes \\
\hline
\end{tabular}

\section{Acknowledgments}

The authors would like to thank Dr. Wen Shan Chen and P202 Lab Department of Electronic Engineering Southern Taiwan University of Science and Technology.

\section{References}

[1] O. Ryynanen, J. Kinnunen, J. Lammintakanen, and O. Kuusi, Suomen Terveydenhuollon Tulevaisuudet. Skenaariot Ja Strategiat Palvelujarjestelman Turvaamiseksi, Tulevaisuusvaliokunta. Teknologian Arviointeja 20. Eduskunnan Kanslian Julkaisu 8, Edita Prima oy, 2004 (Finnish).

[2] R. A. Perrin and N. Simpson, "RFID and bar codes-critical importance in enhancing safe patient care," Journal of Healthcare Information Management, vol. 18, no. 4, pp. 33-39, 2004.

[3] A. Lahtela, M. Hassinen, and V. Jylhä, "RFID and NFC in healthcare: safety of hospitals medication care," in Proceedings of the 2nd International Conference on Pervasive Computing Technologies for Healthcare, pp. 241-244, February 2008.

[4] P.-J. Chen, Y.-F. Chen, S.-K. Chai, and Y.-F. Chai, "Implementation of an RFID-based management system for operation room," in Proceedings of the 8th International Conference on Machine Learning and Cybernetics, pp. 2933-2938, IEEE, Baoding, China, July 2009.

[5] A. Ohsaga and K. Kondoh, "Bedside medication safety management system using a PDA and RFID tags," in Proceedings of the 7th International Symposium on Medical Information and Communication Technology (ISMICT '13), pp. 85-89, March 2013.
[6] C.-F. Huang and J.-H. Lin, "A warning system based on the RFID technology for running-out of injection fluid," in Proceedings of the 33rd Annual International Conference of the IEEE Engineering in Medicine and Biology Society (EMBS '11), pp. 2212-2215, IEEE, Boston, Mass, USA, September 2011.

[7] A. Cataldo, G. Cannazza, N. Giaquinto, A. Trotta, and G. Andria, "Development of a remote system for real-time control of intravenous drip infusions," in Proceedings of the IEEE International Symposium on Medical Measurements and Applications (MeMeA '11), pp. 234-237, May 2011.

[8] A. Cataldo, G. Cannazza, N. Giaquinto, A. Trotta, and G. Andria, "Microwave TDR for real-time control of intravenous drip infusions," IEEE Transactions on Instrumentation and Measurement, vol. 61, no. 7, pp. 1866-1873, 2012.

[9] L.-S. Tsay, A. Williamson, and S. Im, "Framework to build an intelligent RFID system for use in the healthcare industry," in Proceedings of the Conference on Technologies and Applications of Artificial Intelligence (TAAI '12), pp. 109-112, IEEE, Tainan, Taiwan, November 2012.

[10] K. Finkenzeller, RFID Handbook: Fundamentals and Applications in Contactless Smart Cards and Identification, Wiley \& Sons, New York, NY, USA, 2nd edition, 2003.

[11] S. F. Wamba and E. W. T. Ngai, "Unveiling the potential of RFID-enabled intelligent patient management: results of a Delphi study," in Proceedings of the 44th Hawaii International Conference on System Sciences (HICSS-44 '10), Kauai, Hawaii, USA, January 2011.

[12] X. Xuan, L. Lv, and K. Li, "A miniaturized meandered dipole UHF RFID tag antenna for flexible application," International Journal of Antennas and Propagation, vol. 2016, Article ID 2951659, 7 pages, 2016.

[13] Y. Yao, J. Yu, and X. Chen, "Study on the optically transparent near-field and far-field RFID reader antenna," International Journal of Antennas and Propagation, vol. 2014, Article ID 149051, 5 pages, 2014.

[14] A. Kiourti and K. S. Nikita, "Miniature scalp-implantable antennas for telemetry in the MICS and ISM bands: design, safety considerations and link budget analysis," IEEE Transactions on Antennas and Propagation, vol. 60, no. 8, pp. 3568-3575, 2012.

[15] D. K. Cheng, Field and Wave Electromagnetics, Addison-Wesley, Boston, Mass, USA, 1989.

[16] https://support.impinj.com/hc/en-us/articles/202756908-Monza4-RFID-Tag-Chip-Datasheet.

[17] C.-F. Huang, J.-Q. Zhan, and T.-Y. Hao, "RFID tag antennas designed by fractal features and manufactured by printing technology," in Proceedings of the 1st International Workshop on RFID Technology-Concepts, Applications, Challenges Workshop, Funchal, Portugal, June 2007. 


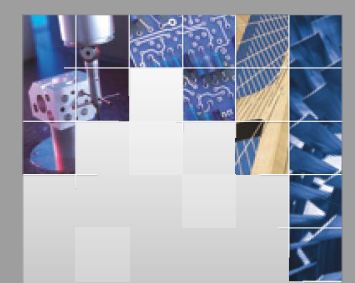

\section{Enfincering}
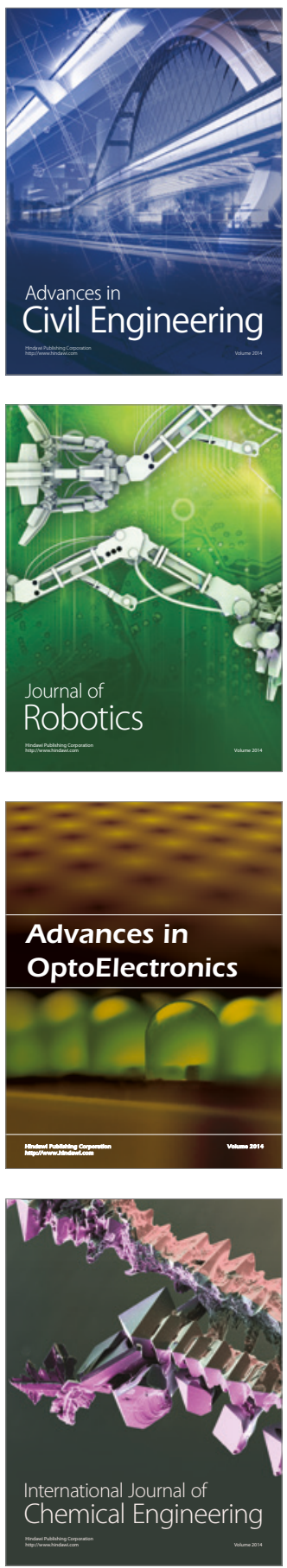

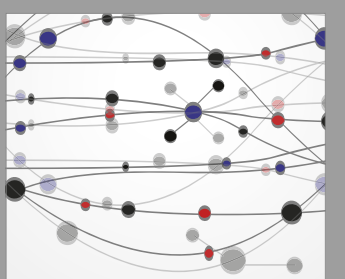

The Scientific World Journal

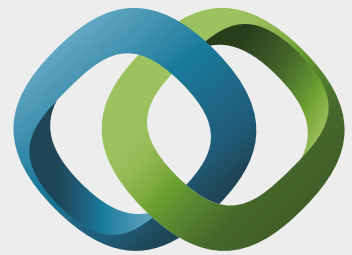

\section{Hindawi}

Submit your manuscripts at

https://www.hindawi.com
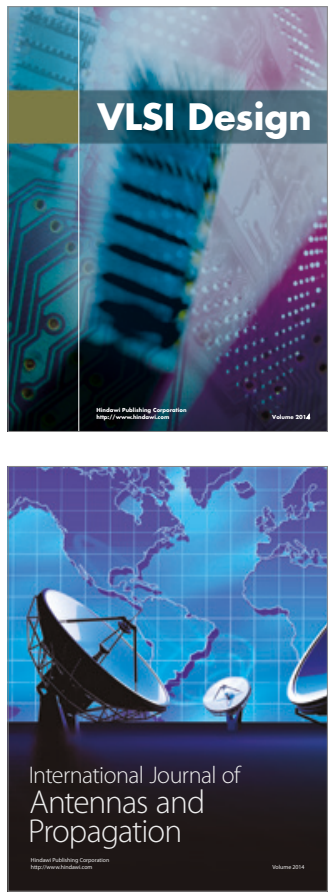

\section{Rotating}

Machinery
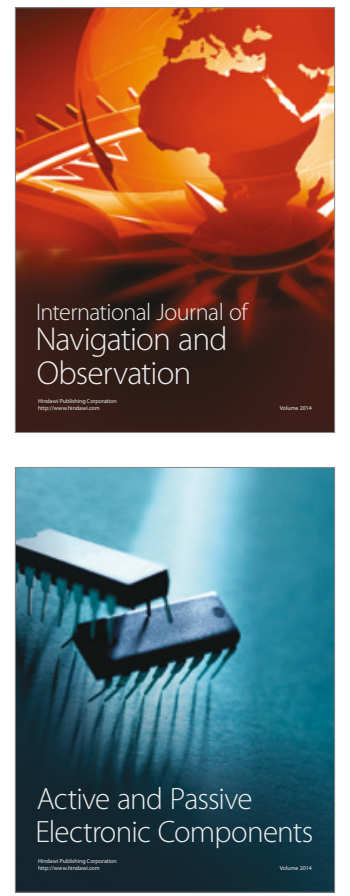
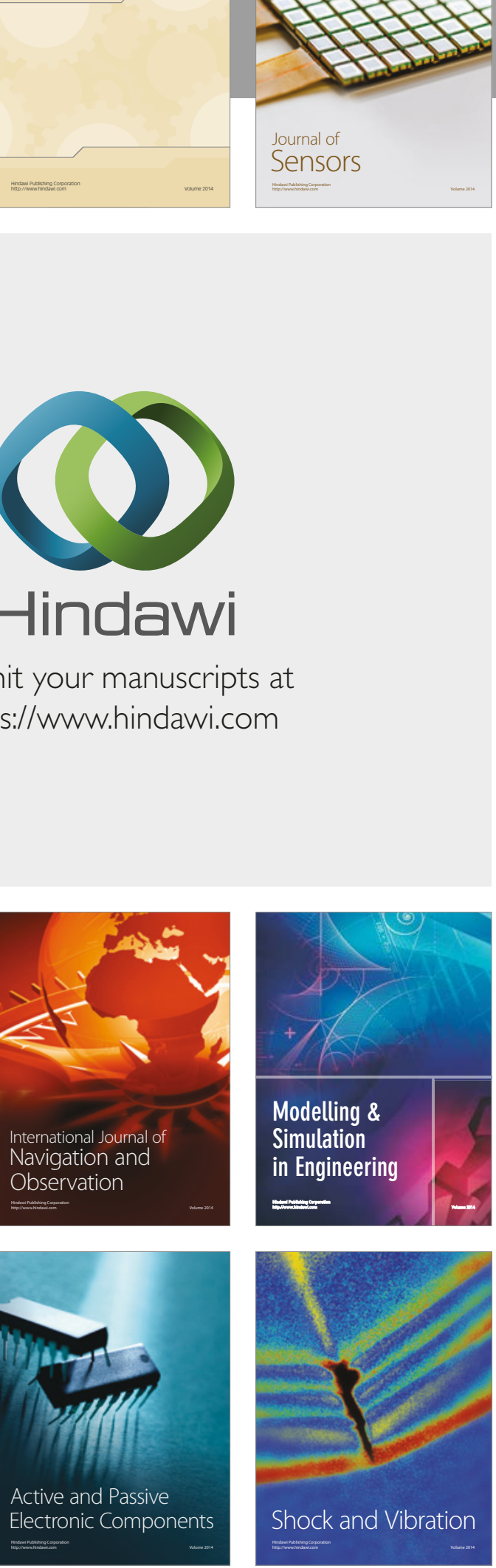
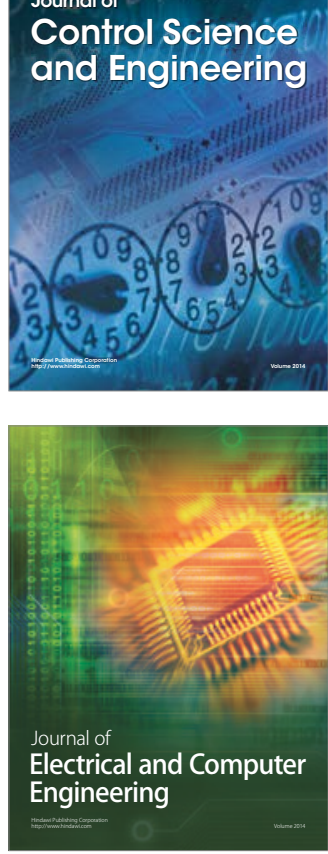

Distributed

Journal of

Control Science

and Engineering
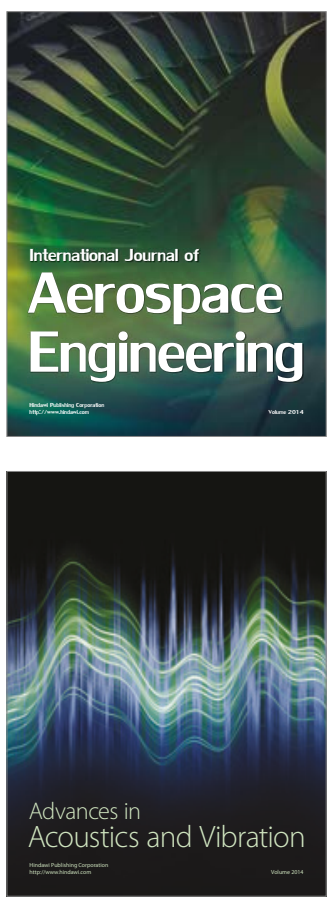

Sensor Networks 